Psicologia \& Sociedade; 20 (2): 257-266, 2008

\title{
AGENTES COMUNITÁRIOS DE SAÚDE: SENTIDOS ACERCA DO TRABALHO EM HIV/AIDS
}

\author{
Nara Helena Lopes Pereira da Silva \\ Cármen Lúcia Cardoso \\ Universidade de São Paulo, Ribeirão Preto, Brasil
}

\begin{abstract}
RESUMO: Este estudo pretende ampliar discussões sobre o trabalho dos agentes comunitários de saúde, na atenção primária, em relação ao HIV/AIDS. Para tal, o objetivo foi dar visibilidade para os sentidos construídos sobre HIV/ AIDS em um grupo com agentes comunitários de saúde. Foi realizada uma entrevista com um grupo de quatro agentes, sendo a mesma gravada, transcrita e analisada na perspectiva do construcionismo social. A análise das narrativas informa como os diferentes sentidos atribuídos ao longo da história da epidemia se fazem presentes nas concepções e no trabalho com HIV/AIDS, a saber: o preconceito ancorado pelo discurso científico; as relações de gênero implicadas no trabalho; os valores contemporâneos atrelados à perfeição e juventude. Destaca-se que tais sentidos construídos conjuntamente na interação grupal, interpretam e constituem o fazer saúde. Assim, conclui-se que a criação de espaços para a troca dialógica entre os profissionais possibilita problematizar sentidos aparentemente cristalizados no que se refere a temática do HIV/AIDS.
\end{abstract}

PALAVRAS-CHAVE: Estratégia de saúde da família; agente comunitário de saúde; HIV/AIDS; construcionismo social

\section{COMMUNITY HEALTH AGENTS: MEANINGS IN HIV/AIDS WORK}

ABSTRACT: The present study intends to extend discussions about the community health agents work in the primary attention, concerning HIV/AIDS. For this purpose, the objective was to give visibility to the constructed meanings regarding HIV/AIDS in a group of community health agents. A group interview was conducted with four agents. The interview was tape-recorded, transcribed and analyzed in the perspective of social constructionism. The analysis of the narratives informed how the different meanings attributed throughout the history of the epidemy are present in conceptions and in the work with HIV/AIDS, namely, the prejudice anchored by the scientific discourse; gender issues involved in work relations; contemporary values expressed in the ideals of perfection and youth. We emphasize that these meanings jointly constructed with group interaction, interpret and constitute health care. It is concluded that the creation of spaces for dialogical exchanges among professionals makes possible to question meanings apparently crystallized in relation to the thematic of HIV/AIDS.

KEYWORDS: Family health; community health agent; HIV/AIDS; social constructionism.

\section{A Epidemia do HIV/AIDS}

Este estudo é um convite para a reflexão crítica em busca de formas alternativas de entendimento do HIV/ AIDS, por meio do construcionismo social (Gergen \& Mcnamee, 1998). As concepções construcionistas buscam pelas implicações de determinadas descrições e pela possibilidade de construções alternativas. O foco está na construção social da realidade, assim a definição da doença e as formas de tratamento perdem o seu caráter ontológico (Rasera \& Japur, 2001). De acordo com Gergen (1985), a pesquisa construcionista “...preocupase principalmente em explicar os processos pelos quais as pessoas descrevem, explicam ou dão conta do mundo (incluindo elas mesmas) no qual vivem" (p. 266). A lin- guagem, nesse contexto, é concebida enquanto prática social, uma vez que assume a centralidade nos processos de dar sentido ao mundo. Nessa perspectiva, faz-se importante ressaltar os sentidos construídos socialmente e historicamente acerca da epidemia, que informam as vozes sociais presentificadas nas ações em saúde.

As primeiras descrições do Vírus da Imunodeficiência Humana (HIV) ocorreram no início da década de 1980 e foram associadas a grupos específicos, como pessoas com comportamentos sexuais considerados desviantes e usuários de drogas. Tais entendimentos contribuíram para a disseminação do conceito de "grupo de risco", configurando um cenário no qual a infecção passou a ser 
vista como a doença “do outro", estigmatizando determinados grupos sociais. Contribuiu, ainda, para que pessoas não pertencentes a estes grupos subestimassem o risco de infecção da doença (Guerra, Vera, \& Ribeiro, 2002; Mann \& Tarantola, 1996).

$\mathrm{Na}$ tentativa de desviar de concepções estigmatizantes e em busca de ações mais efetivas, emergiu, em fins da década de 1980, a noção de "comportamento de risco". Porém, tal conceito provocou a individualização da epidemia, contribuindo para a noção de culpabilização, ou seja, atribuição da responsabilidade pela doença ao indivíduo, a quem caberia identificar e evitar situações e comportamentos de risco (Esposito \& Kahhale, 2006; Mann \& Tarantola, 1996).

O isolamento do agente viral e o desenvolvimento de drogas anti-retrovirais combinadas (o coquetel) possibilitaram diversos avanços tecnológicos na década de 1990. Houve uma queda da mortalidade imediata, melhora dos indicadores da imunidade e recuperação das demais infecções associadas, favorecendo o aumento da longevidade e da qualidade de vida aos portadores do vírus do HIV (Ayres, França Júnior, Calazans, \& Saletti Filho, 1999).

Tais inovações contribuíram para ampliar a discussão sobre a importância de incluir a dimensão psicossocial na abordagem. Nesse sentido, desenvolveu-se o conceito de vulnerabilidade, em fins de 1990, com foco nas condições sociais de vida. A vulnerabilidade enfatiza a inter-relação entre fatores individuais, sociais e políticos, que favorecem ou dificultam a exposição de uma pessoa ou população ao HIV/AIDS (Barros, 2002). A epidemia passa a ser entendida sob a perspectiva de uma sinergia de diversidades macro e micro estruturais, tais como: a superação das desigualdades sociais, econômicas e raciais, dos preconceitos de gênero e classe, da marginalização de populações, além da necessidade de respeito aos direitos humanos e do exercício da cidadania.

Nesse contexto, as estratégias de prevenção e controle da doença associadas aos avanços da terapia antiretrovirais têm gerado modificações nos aspectos epidemiológicos e no prognóstico da epidemia. A Organização Mundial da Saúde ([OMS], 1996) aponta para um aumento de incidência de AIDS em populações consideradas de baixo nível socioeconômico e de escolaridade, bem como o aumento de casos entre os mais jovens e as mulheres.

No Brasil, a adoção da terapêutica combinada antiretroviral reduziu as taxas de mortalidade, mas se fazem presentes as tendências de "pauperização", de feminilização da epidemia de HIV/AIDS e de aumento da transmissão heterossexual (Farias \& Cesar, 2004).

Frente às tendências de aumento da longevidade, aparecem novas questões de ordem psicossociais como, por exemplo, a necessidade de rever os vínculos afetivos, a vivência da sexualidade, da paternidade/maternidade com parceiros com sorologia igual ou diferente. É preciso uma revisão dos objetivos pessoais e profissionais e novas ponderações acerca das expectativas e crenças com relação ao tratamento. Estes e outros questionamentos impactam a vida das pessoas que vivem com HIV/AIDS e dos serviços de saúde que provêem cuidados a estes usuários (Catalan, Meadows, \& Douzenis, 2000; Remor, 2002; Seidl, Zannon, \& Tróccoli, 2005). Cabe, pois, assinalar a necessidade de se dialogar acerca dos saberes e fazeres em relação a epidemia do HIV/AIDS no contexto dos novos serviços que vêm sendo implantados no Sistema Único de Saúde (SUS), em específico na atenção primária.

\section{O Agente Comunitário de Saúde e o HIV/AIDS}

A Estratégia da Saúde da Família (ESF) surge na década de 1990, tendo como desafio promover a reorientação das práticas e ações de saúde de forma integral e contínua. A Estratégia compreende um conjunto de ações de caráter individual e coletivo, que engloba a promoção da saúde, a prevenção de agravos, o tratamento, a reabilitação e manutenção da saúde (Brasil, 2001a).

Na cidade de Ribeirão Preto, os primeiros Núcleos de Saúde da Família, surgiram em 2001, num convênio firmado entre a Universidade de São Paulo e a Secretaria Municipal de Saúde (São Paulo, n.d.). A epidemia do HIV representa importante problema de saúde pública para a cidade, que ocupa a segunda posição do Estado de São Paulo em número de casos de HIV/AIDS (Brasil, 2005).

Na configuração das equipes da ESF, há um médico generalista, enfermeiro e auxiliares de enfermagem, profissionais da área de odontologia e agentes comunitários de saúde (ACS). Especificamente, o agente comunitário de saúde tem como característica peculiar ser um morador da região e desenvolver suas ações nos domicílios da área de responsabilidade e também junto à Unidade Básica de Saúde (UBS), para programação e supervisão de suas atividades (Brasil, 1997).

O agente comunitário de saúde é visto como fundamental na construção da integralidade, na medida em que eles se encontram na posição de integradores de partes, comunidade e serviço de saúde (R. V. B. Silva, Stelet, Pinheiro, \& Guizardi, 2005).

Algumas diretrizes foram formuladas pelo Ministério da Saúde para a atuação do agente comunitário, visando à prevenção da epidemia de HIV/AIDS, a disseminação de informações, a realização de encaminhamentos e avaliação de serviços para atendimento, a saber:

Perguntar às pessoas sexualmente ativas o que elas sabem sobre DSTs e fornecer informações adicionais; identificar e encaminhar pessoas que apresentam sinais ou sintomas dessas doenças; conscientizar sobre o uso da camisinha em todas as relações sexuais; falar sobre a importância do tratamento do parceiro sexual; informar que nem sempre a pessoas com 
DSTs apresentam sinais e sintomas; verificar se as pessoas encaminhadas às unidades de saúde realmente procuraram atendimentos e se foram atendidas, medicadas e orientadas adequadamente. (Brasil, 2001b, p. 1).

Este estudo pretende ampliar discussões sobre o trabalho dos agentes comunitários de saúde em ações voltadas ao cuidado em relação a epidemia do HIV/AIDS. Neste sentido, o objetivo da presente pesquisa foi dar visibilidade para os sentidos produzidos sobre HIV/AIDS em um grupo de agentes comunitárias de saúde.

Dar visibilidade aos discursos sociais presentes nas narrativas desses profissionais da atenção primária permite refletir sobre a construção de ações efetivas em HIV/ AIDS a partir dos diversos entendimentos destes profissionais, bem como problematizar as ações programáticas que vêm sendo desenvolvidas no Brasil. Dentro da perspectiva construcionista, ações de saúde efetivas não são dadas a priori, configuram-se como um processo contínuo de criação de fazeres e de negociação de sentidos, por meio das relações e trocas dialógicas presentes nos microprocessos.

\section{Método}

\section{Construção do Corpus}

Foi realizada uma entrevista em grupo, em um Núcleo de Saúde da Família da cidade de Ribeirão Preto, São Paulo, Brasil. O critério para a seleção deste Núcleo foi à solicitação de um estudo sistematizado sobre a temática do HIV/AIDS, feita pelos profissionais, sobretudo, pelos agentes comunitários, que cotidianamente visitavam famílias vulneráveis. A área referida tem alto índice de usuários de drogas e de repúblicas de profissionais do sexo.

A equipe de agentes dessa Unidade era composta por quatro profissionais, todas mulheres, que aceitaram participar do estudo. Os nomes são fictícios, a fim de preservar a identidade das participantes. Quatro agentes comunitárias de saúde e a pesquisadora constituíram o presente grupo, a saber:

Elaine, 27 anos, casada, agente há cinco anos, nível médio de escolaridade.

Hélia, 42, solteira, agente há cinco anos, nível médio de escolaridade.

Juliana, 31, casada, agente há dois anos, nível médio de escolaridade.

Gabriela, 43, casada, agente há quatro anos, nível médio de escolaridade.

Coordenadora, 24, solteira, psicóloga e pesquisadora.

Os diálogos foram iniciados a partir da pergunta: "O que nós podemos conversar sobre HIV/AIDS?” A entrevista foi áudio-gravada, com o consentimento das partici- pantes. Foi realizada a transcrição na íntegra do material e este foi analisado na perspectiva do construcionismo social. A realização da entrevista em grupo com notações $a$ posteriori, transcrição e análise das narrativas foram realizadas pela pesquisadora responsável, que é psicóloga, com experiência na condução de entrevistas em grupos de profissionais de saúde. O grupo teve a duração de duas horas. Todo o material transcrito foi editado em word, acrescentando numeração nas linhas das falas e também com a edição de cores específicas para cada narrador, a fim de facilitar a visualização do material.

Análise

Conforme sugere Spink e Lima (1999) “. . . com a análise inicia-se uma imersão no conjunto de informações coletadas, procurando deixar aflorar os sentidos, sem encapsular os dados em categorias, classificações e temáticas definidas a priori" (p. 106). Três fases delimitaram a análise do corpus:

1. Pré-análise: contato inicial com as narrativas desde a transcrição e edição do material por meio de leituras contínuas e exaustivas em um processo de produção dos sentidos com a pesquisadora.

2. Análise temática: as seqüências das falas foram divididas em momentos, buscando facilitar a construção de sentidos a partir da interação narrativas/ pesquisadora/ literaturas de base, com um olhar atento para cada enunciado.

3. Análise linear das narrativas: aprofundamento na seqüência longitudinal dos enunciados, a fim de dar visibilidade aos sentidos no grupo, em confrontação com os sentidos proeminentes das fases anteriores de análise.

\section{Resultados e Discussão}

Foram selecionados cinco momentos, a fim de ilustrar algumas vozes sociais presentes no grupo de agentes comunitários de saúde em relação ao HIV/AIDS, em específico, vozes que informam as dificuldades das agentes no diálogo com pessoas que vivem com HIV/AIDS e com casais cujo status sorológico é discordante. Dar visibilidade para tais dificuldades implica refletir sobre o trabalho do agente comunitário de saúde e as propostas da Estratégia de Saúde da Família.

\section{AIDS... Uma Doença Que Está se Alastrando (Hélia, Linha 08)}

Nos enunciados iniciais, o HIV/AIDS é concebido pelo grupo como um assunto difícil, tanto para abordá-lo nas orientações às famílias, quanto na capacidade de entendimento da comunidade, em específico de casais com o status sorológico diferente. 
Coord: “...O que a gente poderia conversar nesse grupo sobre HIV/AIDS?"

Hélia: "O que a gente percebe sobre AIDS, . . . é uma doença que taí [sic], alastrando a cada dia mais, e as pessoas não estão prevenindo adequadamente. É um assunto dificílimo [fala com ênfase], que muitas vezes, pelo menos os que eu visitei, eu fui saber depois de muito tempo, uns eu fiquei sabendo por outras pessoas . . . e abordar esse assunto com as pessoas ainda é muito difícil. A gente vê, lê, eu mesma li muito sobre AIDS, já participei de palestras, de coisas sobre AIDS, a gente tenta [fala com ênfase] passar isso pras pessoas, mas é muito difícil, eles não fazem nada [fala com ênfase] pra prevenir, a maioria dos que eu conheci, tem uns que até hoje, nem o tratamento para cura, não entendem...”

Juliana: "Mesmo porque é um tabu..."

Hélia: "É... Eles não entendem [fala com ênfase] que, a, mas meu marido já tem, eu tenho, não precisamos prevenir. A gente tenta mostrar, pois é" (Linha 6 - 17).

As construções acerca do trabalho com o HIV/ AIDS sinalizam a presença dos discursos difundidos pelo Ministério da Saúde, que define como atribuição do agente: "falar a respeito da importância do tratamento do parceiro sexual; conscientizar sobre a necessidade do uso do preservativo em todas as relações" (Brasil, 2001b, p. 1). Entretanto, as narrativas apontam barreiras para a orientação e conscientização a respeito da importância do tratamento para casais, nos quais as pessoas têm o status sorológico diferente.

$\mathrm{O}$ fato de as pessoas não entenderem [sic] e não se prevenirem [sic] é visto como uma barreira no trabalho do agente. $\mathrm{O}$ ato de prescrever comportamentos a serem seguidos pelas famílias parece não ser suficiente para conscientizá-las sobre as medidas preventivas. Porém, tais narrativas parecem legitimadas pelo discurso científico, na medida em que as agentes participam de cursos e têm acesso a estudos e leituras da área. Concordando com $\mathrm{N}$. E. K. Silva et al. (2002), o tratamento permanece centrado na tradução biomédica, reduzindo o contexto social, cultural, psicológico, emocional do viver com HIV/AIDS a fatores que favorecem ou dificultam o tratamento.

Camargo Jr. (2003) aponta que os profissionais da saúde, sob a influência do modelo médico hegemônico, agem como se as doenças fossem objetos concretos, esvaziados de qualquer significado, sejam estes psíquicos ou culturais, fazendo com que o problema identificado pelo profissional seja diverso da necessidade do usuário.

A incorporação de tais discursos acaba por favorecer a manutenção de práticas assistencialistas, ou seja, que não promovem uma participação ativa e consciente de cada usuário no cuidado e tratamento de sua saúde, reproduz a concepção do HIV/AIDS como uma doença e um tabu e posicionam-nas, a partir de discursos organicistas, no lugar de especialistas que detêm o conhecimento e estão aptas à prescrever.

De acordo com Castanha e Araújo (2006), a AIDS

pode trazer inúmeras conseqüências psicossociais, profissionais, familiares e orgânicas; nessa perspectiva, os autores apontam para a necessidade de inserir os ACS na educação preventiva em saúde, como interlocutores entre gestores e a comunidade.

Para tal, é preciso refletir também sobre a maneira como as atribuições difundidas pelas políticas públicas de saúde do governo federal vêm sendo entendidas e praticadas e sobre o quanto tais entendimentos estão divergindo da proposta mais geral da atenção primária, que preconiza a importância do vínculo, do acolhimento, da proximidade, da politização e da alteridade.

\section{Ele Acha Que Não Tem Nada, Que é Mentira, Que Ele Não Tem (Elaine, Linha 59)}

O grupo caminha na tentativa de entender a não contaminação de casais com status sorológico diferente. Conversar sobre as visitas à moradora que não tem o HIV, que não se previne e mantém um relacionamento com um parceiro que tem o HIV/AIDS, possibilita construções conjuntas acerca das barreiras existentes para o estabelecimento do vínculo entre população e agentes.

Elaine: “...não moram mais na área... eles são os donos... Da casa de travestis, da minha área. É um casal, eles estão juntos já há mais de seis anos, e desde que eu entrei aqui, eu também sei por boca dos outros, soube pela Natália do Hospital, que ele é portador, que ele nunca contava pra ela, e a gente também, eu nunca me senti no direito de contar, porque não foi ele que me contou que tinha. Então eu nunca consegui falar com ela. A gente sempre falava sobre proteção... tempo atrás ela descobriu, começou a exigir, mesmo assim ele não aceitava, aí eles casaram... ele acha que não tem nada, ele acha que é mentira, que ele não tem. Como ele tem e ela não tem, com tanto tempo junto? Mas, agora ela disse que ela não tem mais relação sexual sempre, se ele não quiser usar, não vai ter... o último teste que ela fez aqui deu negativo, pelo menos por enquanto..."

Hélia: "E ele nunca fez teste?"

Elaine: "Ele nem fala no assunto."

Gabriela: "Podia fazer, né, de repente não tem mesmo."

Elaine: "Ele não se trata, não vai no Hospital, não faz nada, não se cuida, eu até chego a pensar que talvez ele não tenha mesmo, pode até ser, não sei, talvez ele não tenha mesmo, talvez ele até pode vir fazer o teste, mas é difícil abordar isso com ele, eu não consigo". (Linha 49 - 72). 
A dúvida diante de conversas indiretas - a agente que soube por outra profissional sobre um morador que vivia com o HIV/AIDS - provoca um silenciamento e pouco investimento em ações, o que implica em pouca potência e barreiras para a construção do vínculo. Saber sobre o status sorológico parece distanciá-las, ao invés de propiciar contextos de cuidado e transformações de realidades e ainda as coloca em uma perspectiva de estranhamento de seus fazeres na saúde, distantes da possibilidade de negociações autênticas entre morador e agente, da construção da alteridade e da proximidade. Como orientar casais com status sorológico diferente sobre tratamento e prevenção em um contexto em que a informação legitimada pelos discursos científicos parece não responder às necessidades trazidas pela comunidade?

Refletir sobre estar vivendo com HIV/AIDS e sobre as maneiras como acontecem as negociações com esse casal com status sorológico diferente possibilita questionarem seus posicionamentos, a partir da interação que ocorre nos microprocessos.

As dificuldades para a aproximação parecem permeadas por pré-concepções do que é ter o HIV, da maneira como se aproxima e se vincula e de conversações indiretas estabelecidas com outros profissionais que, aparentemente, mostram-se aptos a conversar sobre HIV/ AIDS. As narrativas parecem informar o agente comunitário que realiza visitas às famílias, mas que não encontra maneiras de abordar a temática.

Parecem presentificar também vozes que informam as concepções de gênero e de relações de poder, as quais favorecem as conversas sobre prevenção com a esposa e dificultam a aproximação com o marido.

Conforme informam Parker e Aggleton (2001), as questões de gênero nas sociedades latino-americanas caracterizam um complexo sistema ideológico, que organiza relações hierárquicas, com o poder e domínio masculino. As relações se configuram em expressões da noção de domínio da masculinidade, em contraste com a passividade e submissão da feminilidade.

As noções de masculino e feminino construídas socialmente parecem corporificadas na construção do vínculo com casais com status sorológico diferente e no trabalho do agente comunitário de saúde. É preciso considerar que as trocas conversacionais acontecem entre agentes comunitárias/mulheres, o que pode configurar um contexto que facilita o vínculo com a esposa - que realiza o teste, conversa sobre prevenção - mas explicita barreira para cuidado voltado à população masculina.

Por outro lado, a possibilidade de acesso à saúde dessa população - a agente que pode conversar sobre prevenção com a esposa; a esposa que tenta negociar com o companheiro métodos preventivos - anuncia alcances da estratégia. Entretanto, é importante considerar algumas dificuldades, visando um efetivo engajamento com as propostas da atenção primária.

Segundo A. J. Silva e Dalmaso (2002), várias questões sobre a atuação dos agentes comunitários de saúde sugerem a complexidade do desafio a eles proposto, como a diversidade de contextos para a atuação, a amplitude de finalidades que abordam desde a vigilância de situações de risco e a assistência à doença até promoção de saúde e a qualidade de vida; o desenvolvimento de tecnologias de trabalho que permeiem questões relativas à concepção de família e relacionamentos sociais, bem como observações das relações interpessoais, incluindo aqui a relevância de acrescentar discussões acerca das relações de gênero e poder na atenção ao HIV/AIDS.

Mais do que estar perto da comunidade e da equipe, o agente comunitário de saúde pertence a esses dois territórios, podendo ser facilitador da criação de vínculos. Entretanto, o estabelecimento de vínculo com as comunidades deve ser olhado nos aspectos que envolvam as subjetividades, com a legitimação do diferente e a construção de relações autenticas. A ESF inclui a possibilidade de ações que abarquem o cultural, as relações entre as pessoas e as interações entre diferentes nos espaços sociais, na relação de cidadãos junto à comunidade no processo de aprender e ensinar a cuidar da saúde. Estabelece um território comum onde os sujeitos e seus saberes podem interagir e dialogar, em co-responsabilidade social de enfrentar os desafios de uma nova produção de saúde (N. H. L. P. Silva, 2006).

\section{É Mais Fácil Falar de Prevenção Para Quem se Imagina Que Não Tem (Elaine, Linha 75)}

Conversar sobre HIV/AIDS possibilita a emergência de construções sociais que informam a abertura para o trabalho de prevenção com pessoas que transmitem uma imagem de saúde, como, por exemplo, o jovem. As narrativas a seguir informam as dificuldades na construção do vínculo, advindas do contato com o outro que é diferente de mim.

Elaine: "Eu acho que é muito mais fácil você falar de prevenção, da doença, pra quem você sabe que não... Ou que você imagina que não tenha a doença, pra quem você... quem é mais jovem, ou quem você imagina que não tenha. Agora quando é uma pessoa que você já sabe que tem, eu acho que é mais difícil, é mais difícil pra entrar no assunto, principalmente quando a pessoa não te fala, e aí é difícil falar, você tem medo de ofender a pessoa, tem medo de ela se sentir invadida, por que é uma opção de cada uma, né. Por mais que ela saiba o que é a doença, é uma opção dela também se ela quer se tratar ou não".

Juliana: "Se ela quer se prevenir ou não" (Linha 75 81). 
As narrativas presentificam vozes que dizem do jovem não vulnerável, distante do risco da infecção. Torna-se possível se aproximar e conversar com essa população sobre prevenção ao imaginar que entre eles não existam pessoas vivendo com o HIV/AIDS. Tais narrativas parecem indicar o preconceito, constituindo imagens negativas associadas a viver com o HIV/AIDS, bem como re-afirmam as influências culturais do olhar para o ser/ estar saudável relacionado ao ser/estar jovem.

Concordando com Luz (2001), as práticas sintetizadas na categoria saúde estão permeadas pelo universo simbólico contemporâneo, de valorização de representações de juventude, beleza e força que estão atreladas aos valores dominantes na sociedade como o individualismo, o cuidado e valorização do corpo. Tais valores permeiam os sentidos e as práticas em saúde, reafirmando também as concepções advindas do paradigma médico hegemônico. Esse universo simbólico contemporâneo legitima o olhar para o jovem como alguém saudável e, embora nesse contexto possibilite ao profissional da saúde estar próximo, promove o distanciamento de quem vive com o HIV/AIDS e dá pouca visibilidade à possibilidade de atenção a esta pessoa.

Cabe ressaltar que os dados epidemiológicos apresentados pela OMS (1996) apontam para o crescimento da epidemia entre jovens e mulheres, o que destoa do olhar das agentes para a população jovem, uma vez que não a percebe como vulnerável. A concepção das agentes em relação ao jovem como estando distante do risco da infecção aponta, ainda, para as descrições iniciais da epidemia do HIV/AIDS em que a doença foi associada a "grupo de risco", propiciando um contexto em que as pessoas que fogem desse perfil subestimem o risco de infecção (Guerra et al., 2002).

A suspeita de que o interlocutor possa estar vivendo com o HIV/AIDS constrói sentidos sobre o HIV/AIDS, que, por vezes, parece criar barreiras na comunicação do profissional. Quando se sabe quem é portador, falar sobre viver com o HIV/AIDS pode carregar o sentido de invasão da privacidade e ofensa, propiciando o distanciamento cidadão/profissional e marginalização dessas pessoas nos serviços de saúde. A não legitimação da alteridade, da subjetividade e da constituição de vínculo com aquele diferente de mim como instrumentos necessários ao trabalho do agente, parece posicionar a pessoa que vive com HIV/ AIDS em um lugar de isolamento e individualização.

Ayres, Calazans, Saletti Filho e França Junior (2003) apontam que o técnico da saúde deve ser um mediador do encontro entre a população e o conjunto de recursos de que uma sociedade dispõe (informações, serviços, insumos...) para construir a saúde. A atitude a que se pretende é aquela em que se coloca perante qualquer outro como um ser humano de igual estatuto e potencial, cuja ênfase é dada ao caráter relacional de qualquer situação de vulnerabilidade. Os autores consideram que a exposição das pessoas ao adoecimento é resultante de um conjunto de aspectos não apenas individuais, mas também coletivos, contextuais e relacionais, que acarretam maior suscetibilidade à infecção e ao adoecimento. Aspectos esses considerados importantes no fazer do agente comunitário de saúde e que poderiam ser amplamente discutidos nos serviços.

\section{Eu Não Sei Se é Preconceito, Eu Não Sei (Hélia, Linha 318)}

Na tentativa de entender a dificuldade em lidar com o doente de AIDS e com o silêncio e temor da epidemia, o grupo conversa sobre o preconceito e desenha uma retrospectiva da infecção com base nos discursos médico-científicos.

Hélia: “...Não sei se é preconceito, eu não sei, a gente conviveu com uma pessoa que tornou um grande amigo da gente, que tinha HIV, morreu... A gente ficou sabendo de outras pessoas, não foi por ele..."

Elaine: "Ele mesmo não falava... Porque quando a pessoa não fala você não se vê no direito de falar, eu penso assim, a vida é sua, a doença é sua, então..."

Hélia: "É... Aí depois a gente fez tudo pra ele [colega vivendo com HIV] voltar, [fala emocionada], aí depois a gente ficou sabendo que ele tinha saído, que ele saiu porque ele achava que as pessoas não iam aceitar ele, e acabou que... nós nunca conversamos com ele sobre esse assunto [chora]..."

Gabriela: "é que muitas pessoas vêm isso como... Safadeza... na época, né, que surgiu, achava que era só homossexual, e era tudo por causa dos travestis... aí depois ficou, ah, é por causa de drogas, só... Tem muita gente que chega, que fala pro ce, que... Ah, é um câncer que não... Sabe... Menos, assim... porque todos eles, se você falar que tá com câncer, todos.. 'Ah...' E tal...'Coitadinho', não sei o que. Você fala que tá com AIDS, 'ah!', tem gente que nem, sei lá, ele acha assim ... porque eu acho que a AIDS é um câncer mais... evoluído, eu acho isso..."

Juliana: "O câncer não tem como se prevenir, e a AIDS você sabe como evita..." (Linha 318 - 350).

Os enunciados referentes às pessoas vivendo com o HIV/AIDS que antes eram afirmativos, agora possibilitam a dúvida, imersos em um desconstruir das narrativas por meio dos microprocessos - eu não sei se é preconceito [sic]. A infecção (re) aparece como um tema proibido e o silenciamento é entendido como o medo da pessoa que vive com HIV/AIDS ver-se rejeitada. Parece haver um sofrimento calado, atrelado ao medo de vivenciá-lo, manifestado de diferentes maneiras, seja através da exclusão social, da morte, do outro e do preconceito. 
Tais narrativas são concordantes ao estudo desenvolvido por Almeida e Labronici (2007) com pessoas portadoras do HIV e que não procuram os serviços de saúde. Os participantes temem ser identificados pelo serviço, principalmente quando sabem que irão encontrar pessoas de seu convívio social para quem não foi revelado seu diagnóstico de HIV. Os autores concluem que tais pessoas antecipam que irão sofrer discriminação e estigmatização e para se protegerem, optam pelo segredo. Esta opção dificulta o estabelecimento da confiança e a procura de cuidados para a sua saúde, aumentando o sofrimento pessoal e a vulnerabilidade para adoecer de AIDS.

A construção social de uma doença proibida dificulta o diálogo, aumenta o sofrimento das pessoas envolvidas e cria barreiras para a alteridade e para a expressão da subjetividade nas relações. Por em dúvida o preconceito, possibilita a construção de novas maneiras de conceber a relação, como a aceitação da condição do outro: a gente fez de tudo pra ele voltar [sic]. Nesse momento, torna-se possível olhar para a subjetividade e expressar os sentimentos, sugerindo a potência do grupo como um lugar de ação e transformação.

$\mathrm{Na}$ tentativa de entender o discurso do preconceito e da discriminação, Gabriela compara a AIDS a outras doenças, como o câncer, ainda que no contexto da dicotomia culpado/vítima e pautada pelo biologicismo. Todavia, parece uma tentativa de diminuir o preconceito social, almejando uma maior inclusão, sobretudo nos serviços de saúde.

As narrativas do grupo parecem pautadas na dialética inclusão/exclusão social em relação a pessoa que vive com HIV/AIDS. Em diálogo com Barreto (2005), as noções de inclusão têm como contrapartida, a exclusão; as discussões sobre incluir/excluir ofuscam a possibilidade de olhar para além da dicotomia e de ampliar para constructos que considerem o processo estrutural na construção da saúde. A dicotomia desconsidera a importância de incluir nos diálogos de saúde a perspectiva da cidadania, atrelada aos ideais de direitos e empoderamento social.

Amparadas pelo discurso organicista e por construções de dicotomias (saúde/doença, vítima/culpado, excluir/incluir, bom/mal), as narrativas situam a pessoa com HIV/AIDS em um contexto de rejeição, vergonha, distanciamento e abandono.

As narrativas das agentes parecem perpassadas pelas vozes sociais que informam o HIV/AIDS. A pessoa vivendo com HIV/AIDS é construída a partir de seus enunciados como alguém que se isola, que tem vergonha de si e tem medo da rejeição do outro. Reproduzem metáforas que representam o medo e a ameaça, favorecendo a manutenção de ações de prevenção e tratamento pouco efetivas.
A Pessoa Com AIDS Hoje Vive Bem (Hélia, Linha 794)

Conversar sobre as barreiras do trabalho das agentes para a construção do vínculo com populações que estão vivendo com HIV/AIDS, dá abertura para expressarem suas concepções sobre outros discursos do HIV/ AIDS, que informam o aumento da sobrevida e da qualidade de vida.

Hélia: "Porque hoje em dia a AIDS não é como quando começou, né, que ia definhando, definhando. Hoje não, a pessoa tá com AIDS, vive bem... Se ela cuida, ela vive normal. Aí quando chega aquela fase, aí sim."

Juliana: "Eu acho que isso piorou bastante."

Coord.: "Você acha que piorou, por quê?"

Elaine: "Exatamente por isso, a expectativa de vida é muito maior, a chance de ter qualidade de vida é muito maior, então esse medo caiu, na época que tudo era terrível, todo mundo morrendo, então o medo era muito grande, hoje o medo acabou, o medo acabou. Hoje você não vê ninguém morrendo de HIV, magro, acabado numa cama, sofrendo pela rua, não vê, a pessoa só fica assim quando ela vai morrer mesmo. Então, isso leva, as pessoas elas só tomam cuidado mesmo, quando elas têm um medo muito grande daquilo". (Linha 793 - 804).

O cuidado é concebido por Elaine como uma condição que imprime ao outro um temor de algo, um fato muito assustador. As abordagens amplamente informadas no início da epidemia, que consideravam a ameaça como uma forma de tratamento e prevenção, parecem legitimadas e presentificadas nas narrativas. Parecem reproduzir a noção divulgada pelas campanhas iniciais de proteção contra AIDS, em que os sentidos informavam a AIDS que mata. Assim, em suas narrativas, a experiência do sofrimento proporciona a possibilidade de autocuidado e prevenção, legitimando a propagação do medo e da exclusão.

Narrativas que apontam a relação entre menor procura por métodos preventivos em virtude do aumento da qualidade de vida e da diminuição do sofrimento da pessoa que vive com HIV/AIDS, implica na necessidade de reflexões sobre a importância de incluir ações para além de tecnologias medicamentosas, que dêem visibilidade a influência dos processos conversacionais equipe/comunidade e que considerem as vozes sociais que emergem dos discursos dos profissionais, sendo estes, construtores de sentidos e realidades.

Estudo realizado sobre representações sociais de HIV/AIDS com pessoas vivendo com HIV/AIDS (Castanha, Coutinho, Saldanha, \& Ribeiro, 2006) aponta que estão intrínsecos os conhecimentos científicos, do senso comum e de valores sociais. Tais representações, se- 
gundo os autores, influenciam e orientam condutas da pessoa que vive com HIV/AIDS em relação à adesão, isolamento, manutenção de relacionamentos interpessoais, sexualidade e até mesmo em relação ao suicídio.

As construções sociais acerca da morte e do morrer pautadas por concepções do mecanicismo, na busca pelo funcionamento perfeito e eterno da "máquina humana", implica em conceber a morte como um fracasso para os profissionais da saúde e para afastá-lo, emerge um sofrimento calado. A pessoa que vive com HIV/AIDS é olhada pelo profissional na perspectiva do doente/sofredor, que se distancia dos corpos referenciados pelos ideais individualistas, competitivos, seja na saúde, na vida cotidiana e nas definições do ser. Tais concepções dificultam as possibilidades de seguir junto nas diversidades e nas adversidades, construindo um contexto marcado pela negação, temor e distanciamento (N. H. L. P. Silva, 2006).

Concordando com Camargo-Borges e Cardoso (2005), a conduta profissional almejada na ESF busca o resgate das múltiplas dimensões da saúde, o que exige a reformulação da postura de intervenção do profissional, assim como a incorporação de outros saberes para compor a produção do cuidado com a saúde.

A relação entre HIV/AIDS e qualidade de vida, cidadania, projetos de vida, aumento da expectativa de vida, contrastam com discursos limitadores no trabalho em prevenção: as pessoas não temem o pior, o HIV/AIDS como medo, morte e luto. No discurso, o cuidado está associado ao medo, distanciando-se da produção do cuidado vista como acesso aos serviços, eqüidade e direito. Nesse sentido, o aumento da qualidade de vida da pessoa vivendo com o HIV/AIDS não é considerado uma possibilidade de transformação de realidades e de legitimação de perspectivas, do exercício da cidadania, do empoderamento social e da alteridade.

A partir desta análise, buscou-se ampliar as reflexões sobre o trabalho com HIV/AIDS das agentes comunitárias, ao dar visibilidade para as implicações de determinadas descrições da doença e também para possibilidades de construções alternativas de sentidos nos microprocessos relacionais.

\section{Considerações Finais}

Este estudo se propôs a dar visibilidade para os sentidos construídos sobre HIV/AIDS em um grupo de agentes comunitárias de saúde, a fim de contribuir para a (re)criação constante dos saberes e dizeres no contexto da epidemia de HIV/AIDS. O referencial teórico metodológico do construcionismo social mostrou-se pertinente para a análise das narrativas das agentes comunitárias de saúde, uma vez que possibilita o estudo das práticas discursivas no cotidiano visando a abertura e a constituição de novas perspectivas em relação ao trabalho com
HIV/AIDS, na atenção primária. Considerando a perspectiva construcionista que visa um aprofundamento e o entendimento acerca da construção dos sentidos no grupo e não a generalização dos mesmos, destaca-se algumas das peculiaridades deste estudo, como a realização de uma entrevista grupal com uma categoria profissional específica, o agente comunitário de saúde, num contexto específico de trabalho, um núcleo de saúde da família.

Algumas das vozes situam a relevância de se refletir sobre as ações pragmáticas do Ministério da Saúde, em específico, no contexto da cidade de Ribeirão Preto. Pensar sobre os discursos acerca das atribuições do agente no tratamento da AIDS quando se refere a pessoa vivendo com HIV/AIDS, sobre como vêm sendo entendidas e implicadas as ações e atribuições na saúde, sobretudo referentes a "Conscientizar sobre o uso da camisinha em todas as relações sexuais" e "Falar sobre a importância do tratamento do parceiro sexual" pode ser útil para que possamos caminhar para a integralidade em saúde.

Estar em grupo, conversando sobre as dificuldades encontradas no trabalho com casais com status sorológico diferente, em dialogia com as vozes advindas da comunidade, parece favorecer a problematização e a reflexão acerca da naturalização de práticas, tendo em vista a possibilidade de interanimação dialógica entre os participantes que puderam rever posicionamentos e concepções. Nesse sentido, o grupo, na perspectiva construcionista social, pode se constituir em um espaço de desconstrução das formas hegemônicas de se conversar sobre HIV/AIDS e se estabelecer como um espaço que possa produzir outras descrições e modos de trabalho. Busca-se, pois, espaços de legitimação das diversidades e peculiaridades de cada contexto, a fim de dialogar e refletir sobre ações compatíveis às necessidades específicas da comunidade na qual tais profissionais estão imersos.

A tentativa de se dialogar sobre os diversos entendimentos de questões que permeiam as barreiras do trabalho com pessoas vivendo com HIV/AIDS presentificam algumas vozes que informam: o preconceito ancorado pelo discurso científico do início da epidemia acerca dos sentidos sobre viver com o HIV/AIDS; as relações de gênero implicadas nos contextos relacionais de trabalho; os valores contemporâneos expressos nas idéias de perfeição e juventude; a expressão das vivências pessoais a partir das narrativas construídas conjuntamente.

Retomar historicamente a construção social de sentidos que permeiam as práticas na atenção à saúde, no contexto do HIV/AIDS, possibilita reconhecer que as descrições das agentes sustentam maneiras de intervenção e construção de identidades profissionais.

As conclusões apontam para a necessidade de ampliar tais espaços de trocas dialógicas nas equipes de Saúde da Família, sendo fundamental a sistematização de outros estudos que abarquem também os demais profissionais e usuários. 


\section{Referências}

Almeida, M. R. C. B, \& Labronici, L. M. (2007). A trajetória silenciosa de pessoas portadoras do HIV contada pela história oral. Ciência \& Saúde Coletiva, 12(1), 263-274.

Ayres, J. R. C. M., França, I., Jr., Calazans, G. J., \& Saletti, H. C., Filho. (1999). Vulnerabilidade e prevenção em tempos de AIDS. In R. M. Barbosa \& R. Parker, (Eds.), Sexualidades pelo avesso - Direitos, identidades e poder (pp. 49-72). São Paulo, SP: Ed. 34

Ayres, J. R. C. M., Calazans, G. J., Saletti, H. C., Filho, \& França, I., Jr. (2003). O conceito de vulnerabilidade e as práticas de saúde: Novas perspectivas e desafios. In D. Czenersnia \& C. Machado Freitas (Eds.), Promoção de saúde-Conceitos, reflexões, tendências (pp. 116-138). Rio de Janeiro, RJ: Editora da Fundação Oswaldo Cruz.

Barreto, J. (2005). Bem-aventurados os excluídos? In J. Barreto, $O$ umbigo da reforma psiquiátrica. Cidadania e avaliação de qualidade em saúde mental (pp. 33-52). Juiz de Fora, MG: Editora da Universidade Federal de Juiz de Fora.

Barros, M. (2002). Adolescência e AIDS. In M. Contini, S. Koller \& M. Barros (Eds.), Adolescência e Psicologia: Concepções, práticas e reflexões críticas (pp. 99-111). Brasília, DF: Conselho Federal de Psicologia.

Brasil. (1997). Programa Saúde da Família: Uma estratégia para a reorientação do modelo assistencial (pp. 05-33). Brasília, DF: Autor.

Brasil. (2001a). Guia prático do Programa de Saúde da Família, Parte II. Brasília, DF: Autor. Retrieved March 10, 2006, from http://dtr2004.saude.gov.br/dab/publicacoes.php

Brasil. (2001b). Informes da Atenção Básica, 11. Brasília, DF: Autor. Retrieved June 20, 2006, from http://dtr2004.saude.gov.br/ dab/documentos/informes/psfinfo11.pdf

Brasil. (2005). Programa Nacional de DST e AIDS. Boletim Epidemiológico, 2(1). Retrieved December 10, 2005, from http:/ / w w w . A I D S.gov. b r / d a t a / P a g e s / LUMIS9A49113DPTBRIE.htm

Camargo-Borges, C., \& Cardoso, C. L. (2005). A Psicologia e a estratégia Saúde da Família: Compondo saberes e fazeres. Psicologia \& Sociedade, 17(2), 26-32.

Camargo, K. R., Jr. (2003). Biomedicina, saber \& Ciência: Uma abordagem crítica. São Paulo, SP: Hucitec.

Catalan, J., Meadows, J., \& Douzenis, A. (2000). The changing pattern of mental health problems in HIV infection: The view from London, UK. AIDS Care, 12(3), 333-341.

Castanha, A. R., \& Araújo, L. F. (2006). Representações sociais de agentes comunitários de saúde acerca da AIDS. Psicologia: Teoria e Prática, 8(1), 17-30.

Castanha, A. R., Coutinho, M. P. L., Saldanha, A. A. W., \& Ribeiro, C. G. (2006). Aspectos psicossociais da vivência da soropositividade ao HIV nos dias atuais. Psico, 37(1), 47-56.

Esposito, A. P. G., \& Kahhale, E. M. P. (2006). Profissionais do sexo: Sentidos produzidos no cotidiano de trabalho e aspectos relacionados ao HIV. Psicologia: Reflexão e Crítica, 19(2), 329339.

Farias, N., \& Cesar, C. L. G. (2004). Tendências da morbi-mortalidade por AIDS e condições socioeconômicas no Município de São Paulo, 1994 a 2001. Revista Brasileira de Epidemiologia, 7(4), 489-502.

Gergen, K. J. (1985). The social constructionist movement in modern psychology. American Psychologist, 40, 266-275.

Gergen, K. J., \& Mcnamee, S. (1998). A terapia como construção social. Porto Alegre, RS: Artes Médicas.

Guerra, M. A., Vera, M. A., \& Ribeiro, A. F. (2002) Epidemiologia. In R. Veronesi \& R. Focaccia (Eds.), Tratado de Infectologia (pp. 88-99). São Paulo, SP: Atheneu.

Luz, M. T. (2001). Políticas de descentralização e cidadania: Novas práticas de saúde no Brasil atual. In R. Pinheiro \& R. A. Mattos (Eds.), Os sentidos da integralidade na atenção e no cuidado à saúde (pp. 17-38). Rio de Janeiro, RJ: Abrasco.

Mann, J., \& Tarantola, D. (1996). AIDS in the world II. New York: Oxford University Press.

Organização Mundial de Saúde. (1996). The status and trends of the Global HIV/AIDS Pandemic. Final Report of the Official Satellite Symposium of XI International Conference on Aids, Vancouver, Canada.

Parker, R., \& Aggleton, P. (2001). Estigma, discriminação e AIDS: Vol. 1. ABIA Cidadania e Direitos (pp. 7-43). Rio de Janeiro, RJ: ABIA.

Rasera, E. F., \& Japur, M. (2001). Contribuições do pensamento construcionista para o estudo da prática grupal. Psicologia: Reflexão e Crítica, 14(1), 201-209.

Remor, E. A. (2002). Aspectos psicossociais na era dos novos tratamentos da AIDS. Psicologia: Teoria e Pesquisa, 18(3), 283-287.

São Paulo. Secretaria da Saúde do Município de Ribeirão Preto. (n.d.). Doenças: AIDS. Ribeirão Preto, SP: Autor. Retrieved March 20, 2006, from http:// www.saude.ribeiraopreto.sp.gov.br/ssaude/ i16principal.Asp?pagina=/ssaude/doencas/i16doencas.htm

Seidl, E. M. F., Zannon, C. M. L. C., \& Tróccoli, B. T. (2005). Pessoas vivendo com HIV/AIDS: Enfrentamento, suporte social e qualidade de vida. Psicologia: Reflexão e Crítica, 18(2), 188-195.

Silva, A. J., \& Dalmaso, A. S. W. (2002). O agente comunitário de saúde e suas atribuições: Os desafios para os processos de formação de recursos humanos em saúde [Versão eletrônica]. Revista Interface - Debates - Comunicação, Saúde, Educação, 6(10). Retrieved December 20, 2002, from http://www.scielo.br

Silva, N. E. K., Oliveira, L. A., Figueiredo, W. S., Landroni, M. A. S., Waldman, C. C. S., \& Ayres, J. R. C. M. (2002). Limites do trabalho multiprofissional: Estudo de caso dos centros de referência para DST/AIDS. Revista de Saúde Pública, 36(4), 108116.

Silva, N. H. L. P. (2006). AIDS: Saúde da família: Sentidos produzidos em grupo com agentes comunitárias de saúde acerca do HIV/AIDS. Dissertação de Mestrado não-publicada, Faculdade de Filosofia, Ciências e Letras, Universidade de São Paulo, Ribeirão Preto, SP.

Silva, R. V. B., Stelet, B. P., Pinheiro, R., \& Guizardi, F. L. (2005). Do elo ao laço: O Agente comunitário na construção da integralidade em saúde. In R. Pinhero \& A. Mattos (Eds.), Cuidado: As fronteiras da integralidade (pp. 75-90). Rio de Janeiro, RJ: Abrasco.

Spink, M. J., \& Lima, H. (1999). Rigor e visibilidade: A explicitação dos passos da interpretação. In M. J. Spink (Ed.), Práticas discursivas e produção de sentidos no cotidiano - Aproximações teóricas e metodológicas (pp. 93-123). São Paulo, SP: Cortez.

Nara Helena Lopes Pereira da Silva possui graduação em Psicologia pela Universidade de São Paulo (USP) e mestrado pela mesma universidade. É doutoranda na 
Silva, N. H. L. P. da e Cardoso, C. L. "Agentes comunitários de saúde: sentidos acerca do trabalho em HIV/AIDS"

área de atenção primária à saúde e saúde mental pela USP. Endereço para correspondência: Universidade de São Paulo, Faculdade de Filosofia Ciências e Letras de Ribeirão Preto, Departamento de Psicologia e Educação, Av. Bandeirantes, 3900, Monte Alegre, Ribeirão Preto, SP, 14040-901. Tel.: (16) 6023660 . nara.helena@gmail.com

Cármen Lúcia Cardoso possui graduação em Psicologia pela USP, mestrado em Saúde Mental e doutorado em Psicologia pela mesma universidade. Atualmente é professora doutora da USP. Endereço para correspondência: Universidade de São Paulo, Faculdade de Filosofia Ciências e Letras de Ribeirão Preto, Departamento de Psicologia e Educação, Av. Bandeirantes, 3900, Monte Alegre, Ribeirão Preto, SP, 14040-901. Tel.: (16) 602 3660; Fax: (16) 6335668. carmen@ffclrp.usp.br

Agentes Comunitários de Saúde: Sentidos Acerca do Trabalho em HIV/AIDS

Nara Helena Lopes Pereira da Silva e Cármen Lúcia Cardoso

Recebido: 13/03/2007

$1^{\text {a }}$ revisão: $10 / 07 / 2007$

$2^{\mathrm{a}}$ revisão: 06/09/2007

$3^{a}$ revisão: 03/12/2007

Aceite final: 06/12/2007 